\title{
THE AZYGOS VEIN SYSTEM IN THE RAT
}

\author{
MYRON H. HALPERN 2 \\ Departments of Anatomy, University of Michigan, Ann Arbor, \\ and Hahnemann Medical College, Philadelphia ${ }^{2}$
}

THREE FIGURES

The adult pattern of the azygos vein system of various mammals has received the attention of many early investigators (Eustachius, 1561; Bardeleben, 1848; Marshall, 1850; and Morrison, 1879). Since there has not always been agreement among these workers in the patterns described, attempts were made by some of them to try to correlate the patterns on a developmental basis (Bardeleben, 1848; Marshall, 1850; and Parker and Tozier, 1897). Tilney ('12), Kampmeier ('12), Sabin ('14, '15), and Reagan ('19) each described the development of the azygos system of a different mammal. Although there was partial agreement on certain aspects of the embryology, it was not until recently that there has been general accord. Since one of the more significant contributions to the development of the azygos system in the rat (Strong, '36) has never appeared as a journal article and is procurable only as a thesis from the Indiana University Library, it will be included and related to the present description of the adult pattern.

\section{MATERIALS}

To investigate the constancy of pattern and to check fully the points of previous disagreement in the adult pattern, 57 rats were studied by the fluorescent-latex injection technique previously described by the author ('52). Eleven additional

2 The author wishes to thank Dr. Russell T. Woodburne, Department of Anatomy, University of Michigan for his critical reading of this manuseript.

${ }^{2}$ Portion of a dissertation submitted in partial fulfilment of the requirements for the degree of Doctor of Philosophy in the University of Michigan. 
specimens injected with colored vinyl acetate were cleared and embedded in Ward's Bioplastic. Brief note has also been made on the general thoracic venous drainage.

\section{OBSERVATIONS}

The thoracic venous drainage in the rat consists of the internal mammary veins, the visceral venous drainage from the esophagus and the trachea, the azygos vein system (fig. 1), and the vertebral venous plexus.

The visceral venous drainage from the esophagus and the trachea is by a single large vein draining into the dorsal side of the right anterior vena cava opposite the internal mammary vein. The vertebral venous plexus includes an extensive plexiform system of veins surrounding the vertebral column. This latter system, called the "vertebral vein system" by Batson ('42), is defined by him as being composed of all the veins of the trunk wall, the veins of the head and neck, and the major vasa vasorum of the vessels of the extremities, and the veins of the vertebral column. It is a system of valveless vessels which can carry blood in any direction under low pressures. The portion of a similar system of veins which has been demonstrated in the present study with rats, is an extensive midline venous plexus which sends tributaries into the dorsal side of each intercostal vein opposite the neck of the ribs. This vertebral venous plexus forms an anastomotic network of channels around the transverse process of each vertebra and fills in the angular space formed by the neck of the rib, the centrum, and the transverse process of the vertebra. Additional observations were not carried out on this system because the primary emphasis of the present work was on the azygos drainage.

The azygos system in the adult rat exhibits a simple pattern of drainage. The azygos vein lies to the left of the aorta against the body wall near the costal angles. The system begins as paired ascending lumbar veins which, upon entering the thorax, receive the intercostal veins. These ascending veins (azygos and hemiazygos in the chest) extend bilaterally to the level of the 10th intercostal space. Each vein receives the 
drainage of the subcostal (13th), the 12th, the 11th, and the 10th intercostal vein of the respective side (fig. 1).

After receiving the right 10 th intercostal vein, which opens into it opposite the 11th rib, the right ascending trunk or hemiazygos vein crosses the midline. In the cranial portion of its course it passes dorsal to the aorta to empty into the azygos vein above the point of entrance of the left 10th intercostal vein. Caudally the hemiazygos vein ascends lateral to the right sympathetic trunk and crosses behind it dorsally at the lower part of the 10th costal interspace in its course to the azygos vein (fig. 1).

Similarly that portion of the azygos vein receiving the left subcostal vein, the 12 th and the 11th intercostal veins lies lateral to the left sympathetic trunk and crosses it dorsally at the lower edge of the 10th intercostal space. From here it ascends medial to the left sympathetic trunk. In its subsequent upward course it receives the 10th intercostal vein from the left, and the 9th, the 8th, the 7th, and the 6th intercostal veins of both sides (fig. 1). From the left side only, it receives more cephalically the 5 th, the 4 th, and in $1.8 \%$ of the specimens the third intercostal vein. The intercostal veins ( 6 through 9 inclusive) from the right side cross the midline and usually pass dorsal to the aorta to terminate in the azygos vein. At the level of the 5th rib on the left side, the arch of the azygos vein crosses ventral to the left sympathetic trunk to become lateral to it. The azygos vein then curves ventrally to drain into the left anterior vena cava between the third costal interspace and the head of the 4th rib (fig. 1).

The second, third, and 4th intercostal veins remain independent in $7 \%$ of the cases, the second and third intercostal veins opening into the left anterior vena cava (fig. $2 \mathrm{~A}$ ). The left 4th intercostal vein most frequently opens into the arch of the azygos vein opposite the lower border of the 4th space (fig. $2 \mathrm{~B}$ ). The 4 th vein is joined by the third intercostal vein in $35 \%$ of the cases examined (fig. $2 \mathrm{C}$ ). It opens in common with the 5 th intercostal vein in $10.5 \%$ of the specimens (fig. $2 \mathrm{D}$ ). The third intercostal vein joins the second intercostal vein to 


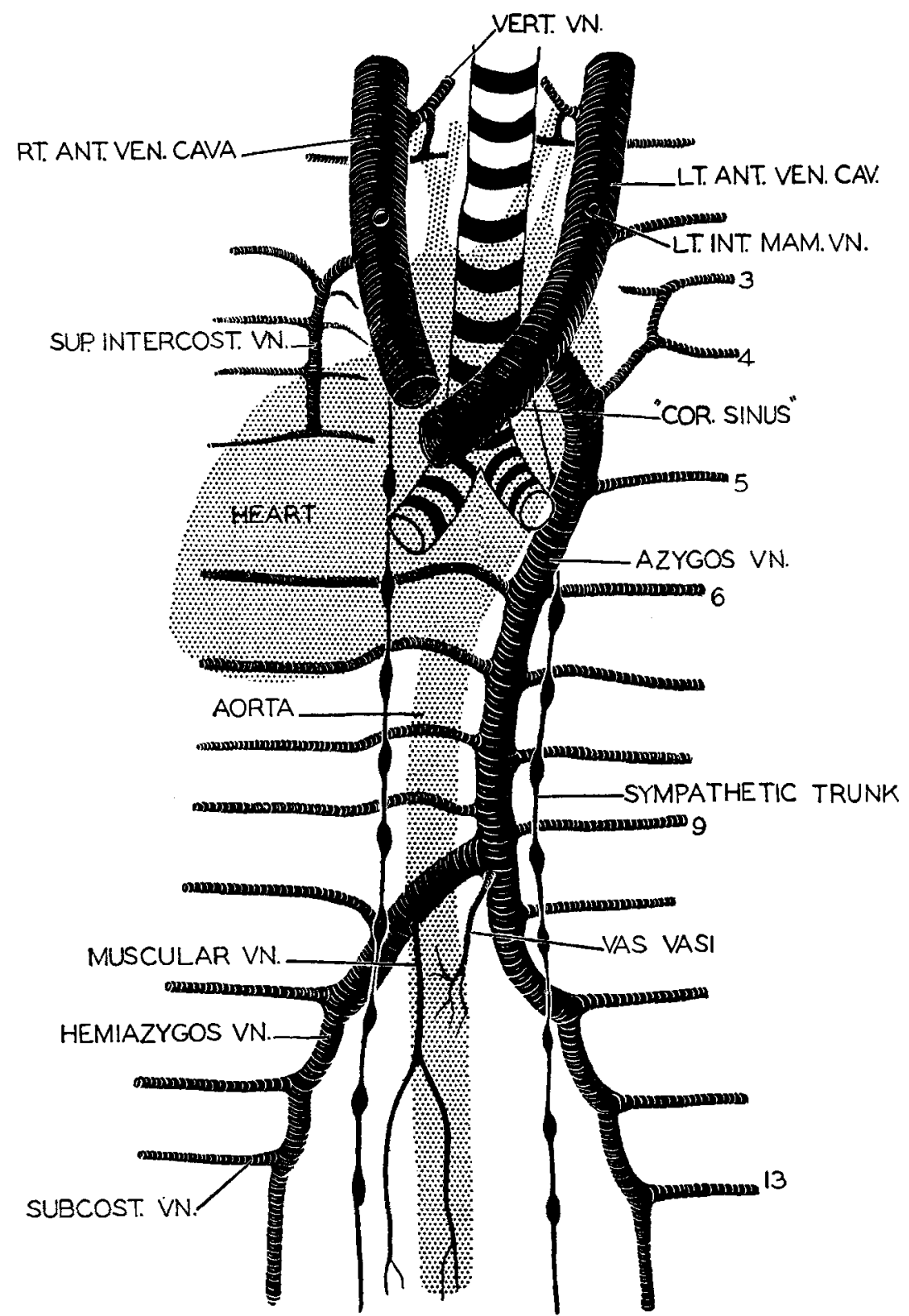

Fig. 1. Diagrammatic plan of the azygos system of veins in the adult rat. 
open together into the left anterior vena cava between the second and third ribs (fig. $2 \mathrm{~B}$ ). This configuration is seen in $38.6 \%$ of the specimens. A combination in which the second and third intercostal veins form a common stem to drain into
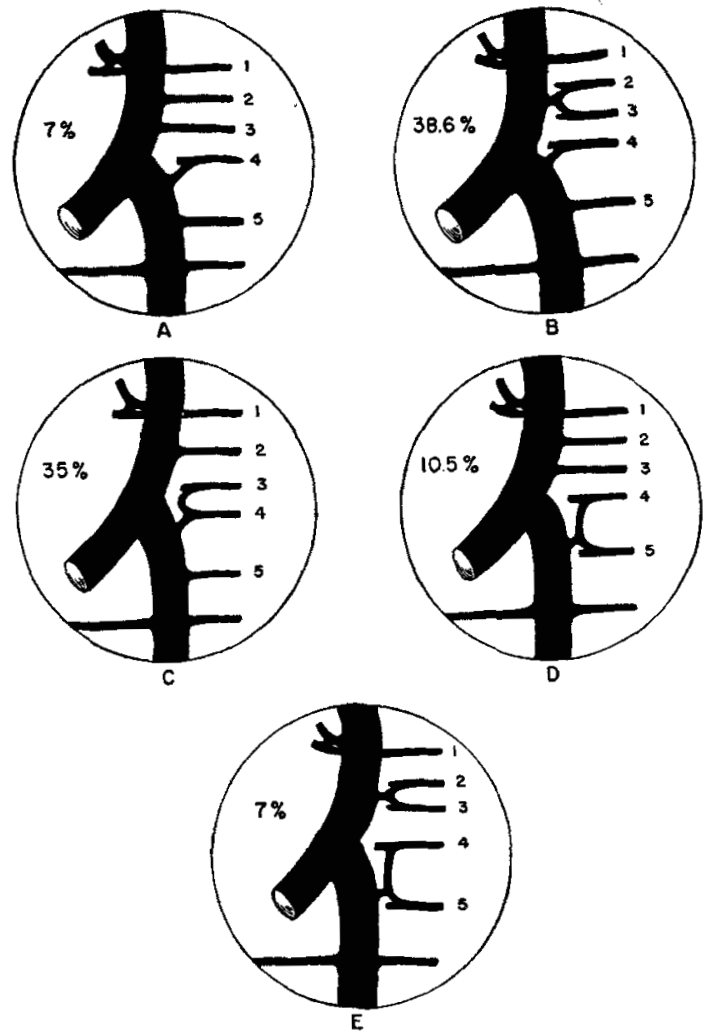

Fig. 2 Variations in the drainage pattern of the left intercostal spaces 1-5 showing the termination of the intercostal veins into the left anterior vena cava and areh of the azygos vein. A to $\mathrm{E}$ shows the incidence of each pattern.

the left anterior vena cava and the 4th and 5th intercostal veins open together into the azygos vein was observed in $7 \%$ of the animals (fig. $2 \mathrm{E}$ ).

On the right side, the intercostal veins from the 5th through the second drain into a longitudinal trunk, the right superior intercostal vein, which like the more caudally placed hemi- 
azygos vein lies lateral to the sympathetic trunk. The former vessel drains into the right anterior vena cava at the level of the second intercostal space as shown in figure 1. Except for the drainage of the first intercostal vein, this corresponds to the patterns deseribed by Greene ('35) and Strong ('36). The first intercostal vein, in the present series, terminated in the vertebral vein of the same side.

A vein arising in the prevertebral lumbar musculature drains into the hemiazygos vein opposite the site of entrance of the right 10th intercostal vein, or into the azygos vein at the site of opening of the hemiazygos vein. A large vas vasis draining the aortic wall enters the azygos vein at the 10th costal space. These two vessels are identified in figure 1.

\section{DISCUSSION}

The azygos pattern described by Strong ('36) corresponds to the configuration detailed here with the exception that she described a superior intercostal longitudinal venous channel, lying lateral to the sympathetic trunk on the left side, and receiving tributaries from the first to the third intercostal spaces. This arrangement was never observed in the present series of rats. Strong described, however, the variable retention of a connection through the 4 th intercostal vein by which the left superior intercostal vein drained posteriorly into the azygos vein. In the present study, the first intercostal vein regularly drained into the vertebral vein, whereas Strong found a more variable pattern in which the termination of the first intercostal vein was in either the superior intercostal vein, the anterior vena cava, or the vertebral vein. Patterns similar to those described by Strong were recorded by Greene ('35). Schneider ('38) described the azygos vein as receiving the hemiazygos from the right side at the 10th costal space in the rat. In his study, the azygos vein also received the three last left intercostal veins and the 4th intercostal vein from both sides.

In the pocket gopher, Hill ('37) found the azygos vein to be reduced in size. It collected blood only from the first three 
right intercostal spaces. The hemiazygos vein, on the other hand, located to the left of the dorsal aorta, was the more important vessel. It received veins from the left intercostal spaces, the last three to 8 right intercostal spaces, and an esophageal vein. The apparent reversal of the azygos and hemiazygos veins in Hill's work is the result of calling a rightsided vessel azygos, regardless of functional significance. In view of the findings in the present work, it is the author's opinion that the designation azygos should be reserved for the major, unpaired, longitudinal thoracic vessel regardless of side. The term hemiazygos may then be properly applied to that vessel of secondary importance which usually drains across the midline into the major one.

The simple pattern of the azygos system of veins in the rat is correlated with the simplicity of its embryology. This fact was realized by the early investigators, some of whom believed that the posterior cardinal veins formed the azygos system while others realized that this is only partially true. One of the first investigators to recognize the double nature of the azygos primordia was Hochstetter (1893). Parker and Tozier (1897) recognized a similar double origin for the azygos vein in the pig. Tilney ('12) described a similar condition for Tragulus embryos.

The work of McClure and Butler ('25) showed that the azygos system in man developed from the posterior cardinal and supracardinal veins. The posterior cardinal veins contribute a minor portion to the system, being only the most cephalic, terminal portion of the azygos vein. According to these authors, the major portion of the azygos and all of the hemiazygos vein in man are formed from the supracardinal veins. Reagan and his co-workers (Reagan, '27a, b; Reagan and Tribe, '27; Reagan and Robinson, '27) have shown that there are probably additional venous lines involved which bear an important relationship to the sympathetic trunk.

In the rat, Strong ('25) described the formation of the hemiazygos vein from two primordia. The posterior cardinal vein contribution formed the proximal portion, and the supracardi- 
nal plexus formed the thoracic portion of the hemiazygos vein. In a subsequent and more detailed study of the azygos system, Strong ('36) showed that the right posterior cardinal vein made no contribution to the adult azygos system. She pointed out that the proximal one to two and one-half segments of the left posterior cardinal vein persist as the corresponding part of the azygos (left) vein in the adult. The factor which determines the amount of the left posterior cardinal vein persisting is the level (usually the 4th intercostal space) at which it receives an enlarged segmental vein which drains the dorsal longitudinal vein. Strong described this latter vessel as a superficial, dorsal venous channel which is fed directly by the vertebral artery (i.e., an arteriovenous anastomosis).

The relations of the supracardinal plexuses are highly characteristic, being lateral to the aorta, ventral to the intersegmental arteries, and medial to the sympathetic trunks. Strong ('36) pointed out that the right supracardinal plexus is poorly developed in the embryo and leaves no adult remains. The Ieft one, on the other hand, persists in thoracic segments 5 to 9 as the corresponding portion of the azygos system. The transverse portion of the hemiazygos vein and the proximal portion of segmental veins 6 through 9 were observed by Strong to pass dorsal to the aorta and terminate in the azygos vein. These transverse connections are derivatives of a primordial plexus of veins situated dorsal to the aorta. She described the entire longitudinal portion of the hemiazygos vein and all of the azygos vein posterior to the 9 th or 10 th intercostal space as being lateral to the posterior cardinal and supracardinal venous lines and therefore they could not be derivatives of them (fig. 3). Strong concluded that they are new formations derived from longitudinal anastomoses between the segmental veins which they drain.

The superior intercostal and the ascending lumbar veins also arise as longitudinal anastomoses between preexisting segmental vessels. These, too, are lateral to the supracardinal and 
posterior cardinal venous lines and cannot be derivatives of them. Similar observations on the azygos system of the rat were recorded by Butler ('50).

Strong's work is confirmed in the present investigation by the adult relationships of the azygos system. Figure 3 shows how the adult configuration reflects the developmental pattern. The embryonic relationship to the sympathetic trunk is maintained throughout. The site where the azygos vein and the left

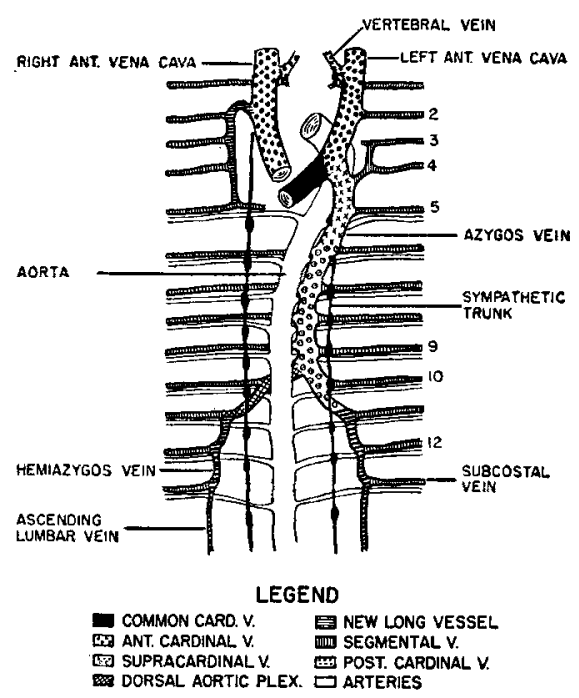

Fig. 3 Diagram of the adult azygos system representing schematically the embryonic structures that have formed the adult system.

anterior vena cava become confluent is the exact position in the embryo where the left anterior cardinal vein and the left posterior cardinal vein unite to form the left common cardinal vein. The region of the 5 th intercostal space marks the place of the post-supracardinal anastomosis.

The azygos vein system in the adult rat is a simple system of veins which reflects the basic pattern followed through the embryology of the region. Variations in the system are directly referrable to its developmental history and are explained logically on that basis. 


\section{SUMMARY}

1. Fifty-seven adult rats were doubly injected and dissected to determine the pattern of the azygos vein system.

2. The thoracic venous drainage of the rat is accomplished by a system of veins which includes the internal mammary veins, a tracheoesophageal vein, the azygos vein, and a vertebral venous plexus.

3 . The azygos system constitutes the main venous channels of the thorax. The intercostal veins of the left side and the 6th through 9th intercostal veins of the right side drain directly into the azygos vein. The 10 th to the 13 th intercostal veins of the right side drain into the hemiazygos vein which in turn drains into the azygos

4. The relationship of the azygos system to the sympathetic trunks is maintained in both the embryo and the adult. It serves as a key to the interpretation of the changes that the embryonic vessels undergo to form the adult azygos system.

\section{LITERATURE CITED}

BARDELEBEN 1848 Ueber Vena azygos, hemiazygos und coronaria cordis bei Säugethieren. Arch. f. Anat. u. Physiol., 1848: 497-501.

BATson, O. V. 1942 The role of the vertebral veins in the metastatic processes. Ann. Int. Med., 16: 38-45.

Butler, H. 1950 The development of the azygos veins in the albino rat. J. Anat., 84: 83-94.

Eustachius, B. 1561 Opuseula Anatomica de vena Sine Pari.

Greene, E. C. 1935 Anatomy of the rat. Trans. Amer. Philos. Soc., 271: 1-370.

Halpern, M. H. 1953 Extracoronary cardiae veins in the rat. Am. J. Anat., 92.

Hilt, J. E. 1937 Morphology of the Pocket Gopher Mammalian Genus Thomomys. Univ. Cal. Pub. Zool., 42 : 81-172.

HochsteTter, F. 1893 Beiträge zur Entwicklungsgeschichte des Venensystems der Amnioten. III. Säuger. Morph. Jahrb., 20: 543-648.

Kampareier, O. F. 1912 The development of the thoracic duet in the pig. Am. J. Anat., $13: 401-475$.

McClure, C. F. W., AND E. G. Butler 1925 The development of the rena cava inferior in man. Am. J. Anat., $35: 331-383$.

Marshall, J. 1850 On the development of the great anterior veins in man and mammals. Philos. Trans. Roy. Soe., 140: 133-170.

MorRison, B. G. 1879 The arrangement of the azygos and superior intercostal veins in the thorax. J. Anat. and Physiol., 13: 346-349. 
PARker, G. H., AND C. H. Tozier 1897 The thoracie derivatives of the posterior cardinal veins of swine. Bull. Mus. Comp. Zool., Howard Univ., 31: $133-144$.

REAGAN, F. P. 1919 On the later development of the azygos vein of swine. Anat. Rec., 17 : 111-125.

1927a Postrenal vena cava not an azygos homologue. Anat. Ree., $35: 48-49$.

$1927 \mathrm{~b}$ The supposed homology of the vena azygos and vena cava inferior considered in light of new facts concerning their development. Anat. Rec., 35 : 129-148.

REAGAN, F. P., AND A. RoBinson 1927 The later development of the inferior vena cava in man and carnivora. J. Anat., $61: 482-484$.

Reagan, F. P., AND M. TRIBE 1927 The early development of the postrenal vena cava in the rabbit. J. Anat., 61: 480-482.

SABIN, F. L. 1914 The development of the azygos veins as shown in injected pig embryos. Anat. Rec., 8; 82-84.

1915 On the fate of the posterior cardinal veins and their relation to the development of the vena cava and azygos in pig embryos. Carnegie Contrib. to Emb., 3: 5-32.

SCHNEIDER, L. A. 1938 The development of the superior caval system in the rat. Anat. Rec., $71: 265-276$.

Strong, Martha T. 1925 The derivatives of the posterior cardinal vein in the rat. Anat. Rec., 31: 320-321.

1936 The development of the azygos system of veins in the white rat. Thesis, Indiana Univ., $75 \mathrm{pp}$.

TILnEy, F. 1912 The development of the axial veins and lymphatics in Tragulus meminna Erxleben. Am. J. Anat., 13: 193-247. 